\title{
PERANCANGAN SISTEM BASIS DATA PADA KLINIK
}

\author{
Indrajani \\ Jurusan Sistem Informasi, Fakultas Ilmu Komputer, Binus University \\ Jl. KH. Syahdan No. 9, Palmerah, Jakarta Barat 11480. \\ indrajani@binus.ac.id
}

\begin{abstract}
The purpose of this research is to analyze and design a database to support Clinic information needs. The methods used in this research are data collection, which uses the search data techniques that includes interviews, documentation, observation, literature study, analysis method and database design that includes conceptual, logical, and physical design. The result of this research is a database system that can save data integrated, clinic information needs, and health services improvement which are patients and community in general. The conclusions that can be drawn from this research are the existence of this database system, so the clinic can manage patient data and checkup transaction, treatment, and payment.
\end{abstract}

Keywords : system, database, patient, treatment

\begin{abstract}
ABSTRAK
Tujuan penelitian ini adalah menganalisis dan merancang basis data untuk mendukung kebutuhan informasi klinik khususnya pada pendaftaran pasien dan pengobatan pasien. Metode yang digunakan adalah metode pengumpulan data menggunakan teknik pencarian data yang meliputi wawancara, mempelajari dokumen, observasi, dan studi kepustakaan. Penelitian ini juga menggunakan metode analisis dan perancangan basis data yang mencakup perancangan basis data secara konseptual, logikal, dan fisikal. Hasil yang dicapai adalah sistem basis data yang mampu menyimpan data terintegrasi, memenuhi kebutuhan informasi klinik, dan meningkatkan pelayanan kesehatan terhadap pasien khususnya dan masyarakat umumnya. Simpulan yang dapat diperoleh dari penelitian ini adalah dengan adanya sistem basis data ini maka klinik dapat mengelola data pasien, transaksi pemeriksaan, pengobatan, dan pembayaran.
\end{abstract}

Kata kunci: sistem, basis data, pasien, pengobatan 


\section{PENDAHULUAN}

Klinik merupakan suatu unit pemeliharaan kesehatan di mana pasien yang berkunjung dapat melakukan konsultasi kesehatan, pemeriksaan kesehatan, dan berobat dengan dokter yang praktek setiap hari, kecuali hari minggu harus dengan perjanjian dengan dokter terlebih dahulu. Pelayanan kesehatan yang tersedia di klinik memfokuskan pada penyakit umum.

Saat ini masih banyak klinik yang menggunakan pendekatan berbasis file (file-based approach) dalam mengelola data. Dengan pendekatan ini, terdapat beberapa masalah yang dihadapi, yaitu antara lain data menjadi tersebar dan terisolasi sehingga sulit mencari dan mengontrol data, duplikasi data sehingga banyak data yang sama dan tidak tahu mana data yang akan dipakai, dan data tidak sesuai dengan keadaan yang sebenarnya. Dampak lain akibat penggunaan pendekatan berbasis file adalah penurunan pelayanan kesehatan klinik tersebut pada masyarakat.

Untuk mengatasi masalah-masalah tersebut diperlukan suatu perancangan sistem basis data agar dapat meningkatkan pelayanan klinik. Penggunaan sistem basis data mampu menyimpan dan mengontrol data pasien dan traksaksi yang dilakukan. Dengan demikian siapapun yang berhubungan dengan klinik baik klinik itu sendiri, dokter, pasien, dan masyarakat akan mendapatkan kemudahan dalam memperoleh informasi yang dibutuhkan.

Oleh karena itu, setiap industri rumah sakit atau klinik medis membutuhkan electronic medical record (EMR). Framework EMR yang digunakan adalah framework dari MMRS (Tierney et al., 2002; Tierney et al., 2010) sebagai berikut: (1) registrasi, yaitu mengambil data untuk mengidentifikasi masing-masing pasien, seperti nama, alamat, no telp dan lain sebagainya; (2) encounter data, yaitu data detail pada klinik untuk konsultasi dengan dokter; (3) data dictionary, yaitu data yang disimpan seperti diagnosis penyakit, obat-obatan yang diberikan beserta dosisnya dan juga tes-tes yang dilakukan; (4) report, di mana data yang diolah menjadi laporan untuk pihak-pihak terkait dalam bidang kesehatan.

\section{METODE}

Metode penelitian yang digunakan adalah pengumpulan data, analisis, dan perancangan basis data. Teknik yang digunakan dalam pengumpulan data ini mencakup wawancara, mempelajari dokumen, observasi, dan studi kepustakaan (Indrajani, 2008, 92 ). Wawancara dilakukan pada bagianbagian yang akan menggunakan sistem basis data yang diusulkan, yaitu bagian administrasi, dokter, perawat, pasien, dan pelanggan. Pertanyaan-pertanyaan yang akan ditanyakan akan disiapkan terlebih dahulu sebelum wawancara berlangsung. Sifat yang akan digunakan adalah gabungan antara pertanyaan tertutup dan terbuka. Untuk mendapatkan data dan informasi mengenai kebutuhan pengguna secara lengkap, dilakukan juga pengumpulan dokumen-dokumen berupa contoh-contoh formulir seperti registrasi pasien, pendataan transaksi yang terjadi seperti rawat inap dan rawat jalan, laporan-laporan medis pasien, buku pasien, dan daftar dokter, karyawan, dan pasien. Selain itu juga dilakukan observasi langsung ke lapangan agar memahami sistem pada klinik secara nyata.

Metode berikutnya adalah metode analisis, di mana dilakukan analisis kebutuhan data dan kelemahan dari sistem yang sedang berjalan.

Metode terakhir yang digunakan dalam penelitian ini adalah metode perancangan basis data. Dalam metode ini akan dibagi menjadi tiga tahap yaitu (Connolly, 2005, p.439), yaitu perancangan basis data konseptual, perancangan basis data logikal, dan perancangan basis data fisikal. Adapun 
perancangan basis data konseptual adalah perancangan basis-data konseptual proses membangun suatu model dari informasi yang digunakan dalam sebuah perusahaan, terbebas dari segala pertimbangan fisikal. Perancangan basis-data logikal yaitu proses membangun suatu model dari informasi yang digunakan dalam sebuah perusahaan berdasarkan sebuah model data yang spesifik tetapi terbebas dari DBMS tertentu dan pertimbangan fisikal lainnya. Tahapan ketiga yaitu perancangan basis-data fisik adalah proses menghasilkan sebuah deskripsi dari implementasi basis-data pada media penyimpanan sekunder yang mendeskripsikan relasi dasar, organisasi file, dan indeks yang digunakan untuk mengakses data secara efisien, dan setiap batasan integritas terkait dan ukuran-ukuran keamanan.

Keseluruhan tahapan di atas terangkum dalam bagan di bawah ini (Gambar 1)

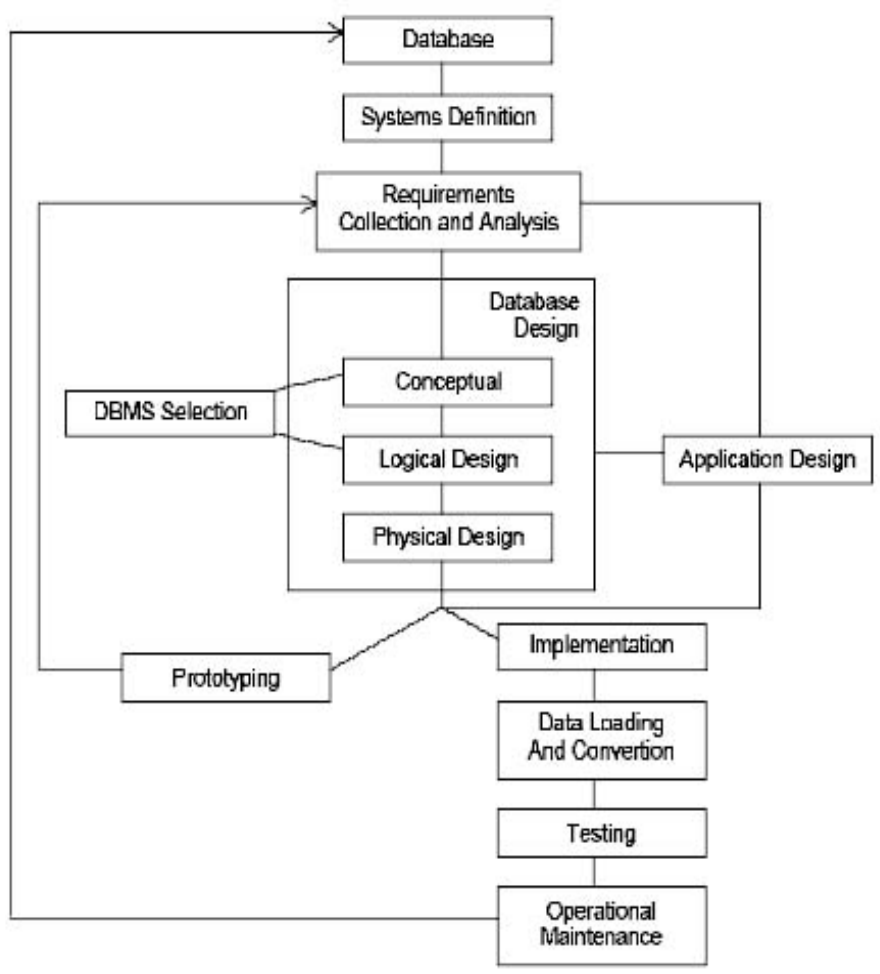

Gambar 1. Tahapan Perancangan Basis Data

\section{HASIL DAN PEMBAHASAN}

\section{Hasil Pengumpulan Data}

Hasil dari pengumpulan data yang dilakukan adalah berupa beberapa prosedur yang terdapat pada klinik, contoh-contoh formulir seperti pendaftaran pasien, laporan-laporan, dan dokumentasi lainnya.

\section{Hasil Analisis}

Dari hasil analisis yang dilakukan, dapat dirumuskan beberapa masalah yaitu kesulitan pencarian data pasien, dokter, karyawan, persediaan maupun transaksi-transaksi. Klinik menyimpan data pasien yang berobat di klinik. Selain itu klinik juga menyimpan data-data transaksi yang telah dilakukan klinik sehingga semakin lama semakin banyak data yang disimpan. Akibatnya, pengguna 
informasi membutuhkan waktu yang lama untuk mendapatkan informasi yang dibutuhkan. Masalah lainnya adalah kesulitan membuat dan menyajikan laporan, pasien berobat, dan transaksi yang cukup banyak dilakukan secara manual sehingga membutuhkan waktu yang cukup lama untuk mengolah informasi yang dibutuhkan. Kemudian belum adanya sistem keamanan data. Data hanya tercatat pada buku dan berkas sehingga data-data penting klinik dapat dilihat, diganti dan diambil oleh siapa saja. Lalu kesalahan pemasukan data. Sistem yang berjalan pada klinik masih manual, ada kemungkinan kesalahan manusia penulisan data.

\section{Hasil Observasi}

Adapun proses pendaftaran pasien adalah sebagai berikut pasien datang ke klinik, pasien melakukan pendaftaran ke bagian administrasi. Bagian administrasi menanyakan kepada pasien telah pernah datang atau baru pertama kali datang. Jika pasien pernah datang maka data sebelumnya akan dipindahkan ke kolom hari ini lalu data pasien akan terdaftar di daftar pasien klinik hari ini. Pasien yang akan berobat pada klinik harus terdaftar terlebih dahulu sebagai pasien klinik. Jika pasien belum terdaftar, petugas administrasi akan memberikan formulir pendaftaran. Apabila pasien dapat untuk mengisi formulir pendaftaran, pasien harus mengisi sendiri formulir pendaftaran tersebut (Kembaran et al., 2008). Jika tidak, dapat diwakilkan oleh keluarga atau siapa saja yang mengantar pasien ke klinik. Setelah formulir diisi, formulir selanjutnya diberikan pada petugas administrasi. Petugas administrasi memeriksa kelengkapan isi formulir pendaftaran. Setelah semuanya telah terisi dengan lengkap, petugas administrasi membuat kartu berobat dan memberikan kartu berobat kepada pasien. Lalu pasien akan masuk ke dalam daftar pasien hari ini dan pasien menunggu giliran untuk berobat dengan menunggu tanda panggilan dari administrasi. Petugas administrasi mencatat data pasien dan keluhan penyakit serta mengurutkan data pasien hari ini sesuai waktu kedatangan pasien dan memanggil pasien berdasarkan urutan yang telah dibuat sebelumnya untuk masuk ke ruangan dokter, Seluruhnya disimpan dalam 1 file dengan Microsoft Excel.

Prosedur lainnya adalah pengobatan pasien sebagai berikut pasien mendapat giliran berobat. Pasien masuk ke ruangan dokter. Rekam medis telah dibuka di 1 file yang telah diisi oleh bagian administrasi dan dibuka oleh dokter. Pasien menceritakan keluhan, gejala, riwayat penyakit pada dokter. Setelah pasien menceritakan keluhan tersebut, dokter melakukan analisa terhadap keluhan tersebut. Selanjutnya dokter melakukan pemeriksaan fisik pasien, berdasarkan hasil analisa dokter tersebut. Selesai melakukan pemeriksaan fisik dokter menuliskan hasil pemeriksaan fisik pasien pada Rekam Medis Pasien di file medical record. Jika dokter merasa perlu melakukan tindakan fisik lanjutan dan tindakan fisik lanjutan tersebut, dapat dilakukan di klinik, dokter menawarkan persetujuan pasien untuk pemeriksaan tindak lanjut. Jika pasien tidak menyetujui untuk diadakanya pemeriksaan lanjut, maka dokter akan menuliskan analisa berdasarkan keluhan pasien. Jika pasien menghendaki adanya pemeriksaan lanjut maka dokter akan melakukan pemeriksaan lanjut, jika tindakan lanjut berupa USG, maka dokter akan melakukan tindakan lanjut di dalam ruangan, karena alat USG memang berada di dalam ruangan dokter. Jika tindakan lanjutan berupa cek Laboratorium atau Rontgent, maka dokter akan menuliskan formulir permintaan pemeriksaan lanjutan kepada bagian terkait, setelah formulir permintaan pemeriksaan lanjut ditulis dokter maka dokter mengarahkan pasien untuk menuju bagian terkait. Kemudian pasien menerima hasil pemeriksaan dari bagian pemeriksaan lanjut (Rontgent atau Laboratorium) maka pasien akan masuk ke dalam ruangan dokter (kasus ini disesuaikan dengan antrian yang ada) ,maka hasil analisa tadi diberikan ke dokter untuk kemudian dianalisa oleh dokter, dan ketika analisa dokter selesai dokter menuliskan hasil analisa di file medical record dan dokter menuliskan resep dokter di file medical record tersebut serta menuliskan resep untuk pasien, kemudian pasien keluar untuk selanjutnya menuju bagian administrasi.

Berikut adalah prosedur pembayaran. Pertama-tama, pasien keluar dari ruang dokter menuju bagian adminstrasi untuk kemudian bagian administrasi mengecek jenis pemeriksaan apa saja yang telah dilakukan pasien yang dilihat dari medical record pasien. Setelah merinci dengan jelas, bagian adminstrasi mencetak rincian pembayaran dan memberikannya kepada pasien. 
Berdasarkan pengumpulan data yang dilakukan, kemudian analisis kebutuhan data, dan kelemahan sistem yang berjalan, dilakukanlah perancangan basis data yang meliputi perancangan konseptual, perancangan logikal, dan perancangan fisikal.

\section{Perancangan Basis Data}

\section{Perancangan Konseptual}

Proses membangun sebuah rancangan informasi yang digunakan dalam suatu perusahaan bebas dari pertimbangan fisikal. Perancangan melibatkan pembuatan suatu model data konseptual dari bagian perusahaan. Model data dibuat menggunakan informasi yang didokumentasikan dalam spesifikasi kebutuhan pengguna. Perancangan basis data konseptual secara keseluruhan bebas dari rincian implementasi seperti software DMBS, program aplikasi, bahasa pemrograman, hardware platform, atau permasalahan fisikal lainnya. Langkah-langkah dalam perancangan basis data konseptual, antara lain mengidentifikasi tipe entitas, mengidentifikasi tipe relationship, mengidentifikasi dan asosiasi atribut suatu entitas, menentukan domain atribut, mengidentifikasi candidate key dan primary key suatu entitas, mengecek model redundansi, dan melakukan validasi model konseptual terhadap transaksi pengguna. Adapun entitas-entitas yang dihasilkan dari tahapan ini terangkum pada Tabel 1 berikut:

Tabel 1

Tipe Entitas

\begin{tabular}{|c|c|c|c|}
\hline Nama Entitas & Alias & Deskripsi & Kejadian \\
\hline Db_pasien & pasien & $\begin{array}{l}\text { Menggambarkan pasien yang } \\
\text { berobat }\end{array}$ & $\begin{array}{l}\text { Semua data pasien yang di periksa } \\
\text { oleh klinik }\end{array}$ \\
\hline Db_karyawan & karyawan & $\begin{array}{l}\text { Menggambarkan karyawan } \\
\text { yang bekerja }\end{array}$ & $\begin{array}{l}\text { Karyawan melakukan aktivitas } \\
\text { kerja yang ada }\end{array}$ \\
\hline Db_dokterPengirim & Dokter pengirim & $\begin{array}{l}\text { Menggambarkan nama dokter } \\
\text { pengirim }\end{array}$ & \\
\hline Db_lab & laboratorium & $\begin{array}{l}\text { Menggambarkan pemeriksaan } \\
\text { laboratorium klinik }\end{array}$ & $\begin{array}{l}\text { Semua data pemeriksaan } \\
\text { laboratorium yang ada di klinik }\end{array}$ \\
\hline Db_usg & Usg & $\begin{array}{l}\text { Menggambarkan data } \\
\text { pemeriksaan USG klinik }\end{array}$ & $\begin{array}{l}\text { Semua data yang berisi } \\
\text { pemeriksaan USG yang ada di } \\
\text { klinik }\end{array}$ \\
\hline Db_rongent & Rontgent & $\begin{array}{l}\text { Menggambarkan data } \\
\text { pemeriksaan rontgent klinik }\end{array}$ & $\begin{array}{l}\text { Semua pemeriksaan rontgent yang } \\
\text { ada klinik }\end{array}$ \\
\hline Db_pemeriksaan & pemeriksaan & $\begin{array}{l}\text { Menggambarkan data } \\
\text { pemeriksaan pada pasien }\end{array}$ & $\begin{array}{l}\text { Semua data yang berhubungan } \\
\text { dengan pemeriksaan pasien }\end{array}$ \\
\hline Db_resep & Resep & $\begin{array}{l}\text { Menggambarkan } \\
\text { pemesanan obat }\end{array}$ & $\begin{array}{l}\text { Semua data yang berhubungan } \\
\text { dengan pemesanan obat }\end{array}$ \\
\hline Db_rekapKlinik & Rekap klinik & $\begin{array}{l}\text { Menggambarkan } \\
\text { administratif dari setiap } \\
\text { pasien }\end{array}$ & $\begin{array}{l}\text { Semua data yang berhubungan } \\
\text { dengan data administratif dari } \\
\text { setiap pasien }\end{array}$ \\
\hline Db_user & Data Karyawan & Data Virtual Karyawan & $\begin{array}{l}\text { Semua data yang berhubungan } \\
\text { dengan data Virtual Pasien }\end{array}$ \\
\hline
\end{tabular}

Di akhir tahap perancangan basis data konseptual ini, dihasilkan sebuah model data konseptual yang benar-benar mewakili view. Adapun model data konseptual yang dihasilkan adalah seperti yang terlihat pada ERD pada Gambar 2 berikut ini :

\section{Perancangan Logikal}

Tahap ini merupakan proses membangun sebuah rancangan informasi yang pada rancangan 
data yang spesifik tetapi masih bebas dari penentuan DBMS dan pertimbangan fisikal yang lain. Pada proses perkembangan model data logikal, model diuji dan divalidasi terhadap kebutuhan pengguna. Tujuan dari tahapan ini adalah untuk menghilangkan fitur-fitur yang tidak kompatibel dengan model relasional. Pada akhir tahapan ini dihasilkan satu model data logikal. Adapun langkah-langkah yang dilakukan dalam merancang basis data logikal, yaitu: (1) menurunkan tabel untuk model data logikal; (2) memvalidasi tabel menggunakan normalisasi; (3) memvalidasi tabel terhadap transaksi pengguna; (4) memeriksa batasan integritas; (5) dan me-review model data logikal lokal dengan pengguna.

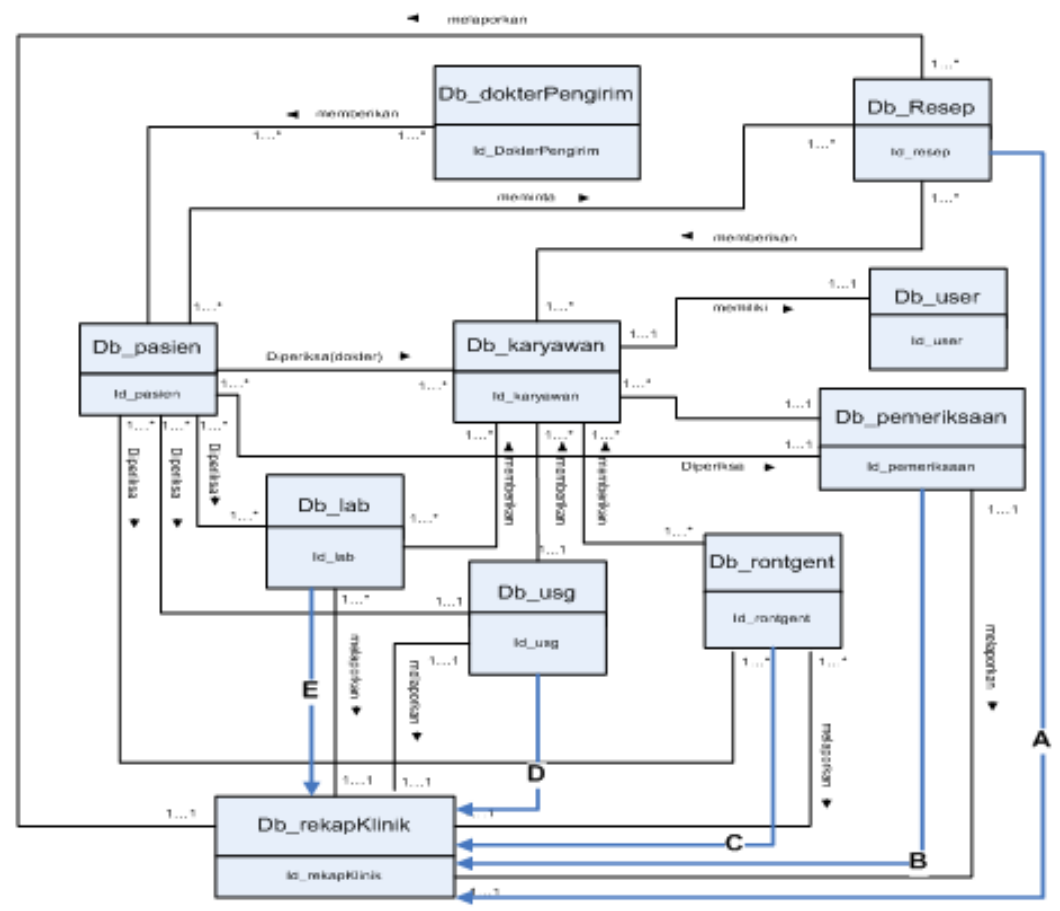

Gambar 2. Validasi model konseptual terhadap transaksi pengguna.

Contoh tipe relasi kuat antara lain: Db_Pasien (Id_pasien, NamaPasien, AlamatPasien, UmurPasien, JenisKelaminPasien, permintaanPasien)

Primary Key Id_pasien

Db_Pemeriksaan ( Id_pemeriksaan, KeluhanSakit, Diagnosa, Resep )

Primary Key Id_pemeriksaan

Seluruh tabel yang dihasilkan pada langkah sebelumnya seharusnya telah berada dalam 3NF. Namun, jika terdapat tabel yang belum 3NF, maka tabel tersebut perlu dinormalisasi. Contohnya :

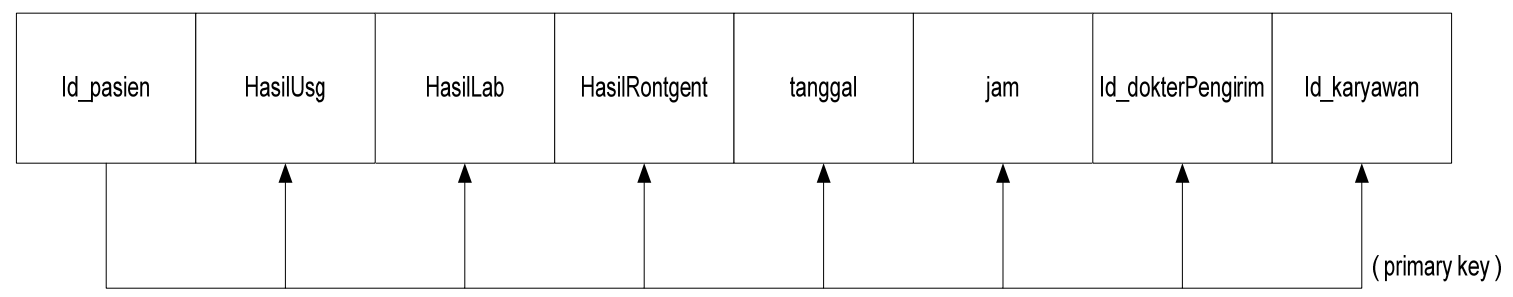

Gambar 3. Normalisasi “Db_Pasien”. 
Db_Pasien

$1 \mathrm{NF}$

Dalam relasi Db_pasien tidak terdapat repeating group.

2NF

Dalam relasi Db_pasien tidak terdapat ketergantungan parsial.

3NF

Dalam relasi Db_pasien tidak terdapat ketergantungan transitif.

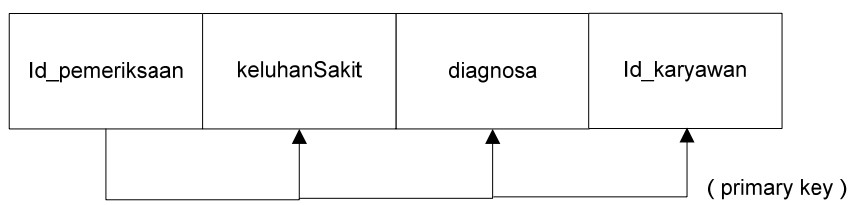

Gambar 4. Normalisasi “Db_Pemeriksaan”.

Db_pemeriksaan

1NF

Dalam relasi Db_pemeriksaan tidak terdapat repeating group.

2NF

Dalam relasi Db_pemeriksaan tidak terdapat ketergantungan parsial. 3NF

Dalam relasi Db_pemeriksaan tidak terdapat ketergantungan transitif. (Gambar 5):

Berikut adalah model data logical yang dihasilkan seperti yang terlihat pada ERD di bawah ini

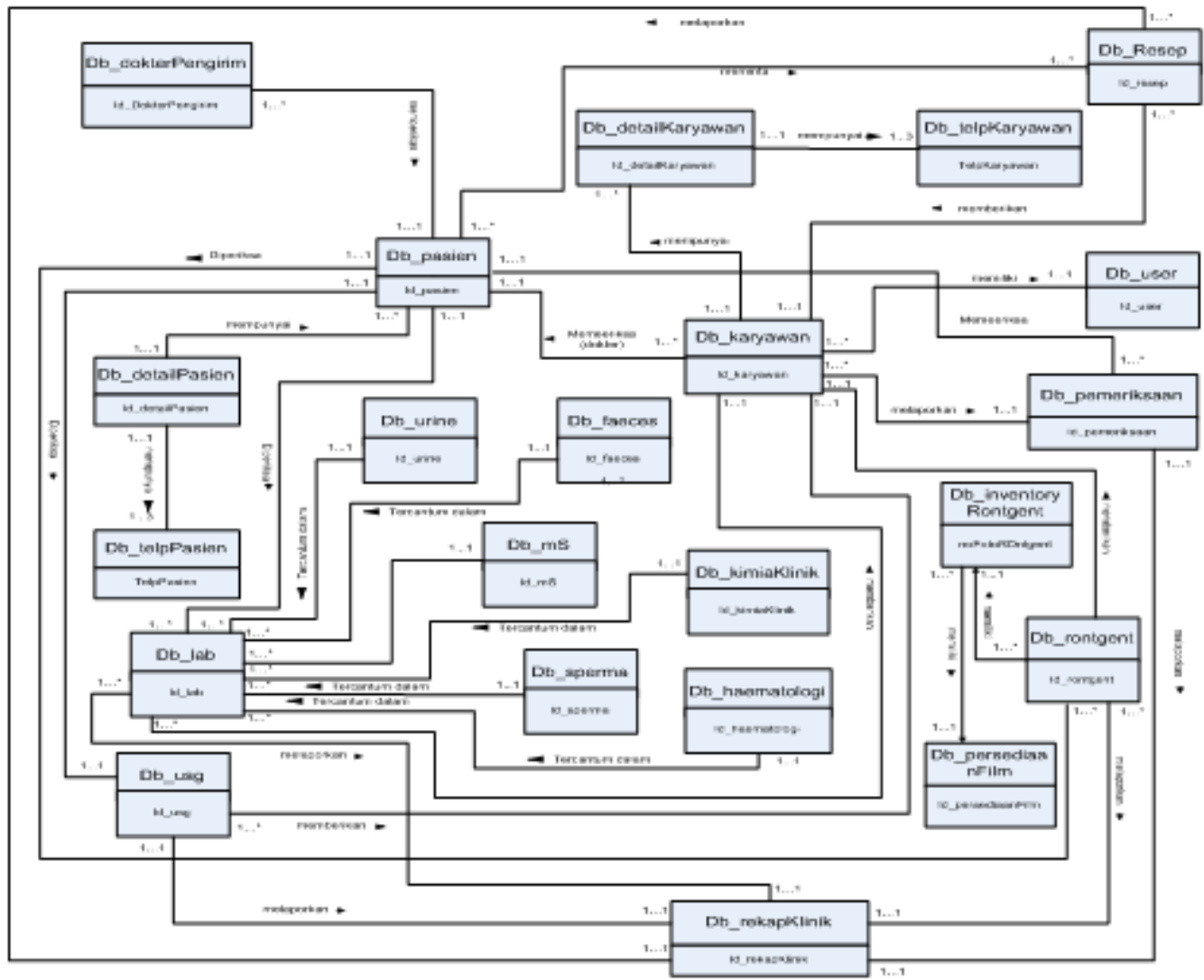

Gambar 5. ERD perancangan basis data logikal setelah normalisasi. 


\section{Perancangan Fisik}

Perancangan basis data fisik merupakan proses untuk memutuskan bagaimana struktur logikal diimplementasikan secara fisik (sebagai relasi/ tabel) ke target DBMS. Adapun langkah-langkah yang dilakukan dalam perancangan basis data fisik yaitu: (1) merancang relasi dasar; (2) memilih organisasi file; (3) memilih indeks; (4) memperkirakan kebutuhan disk space; (5) merancang Mekanisme Keamanan.

Merancang relasi dasar bertujuan untuk mengidentifikasikan relasional basis data dalam model data logikal pada DBMS dengan menggunakan Database Design Language (DBDL). Adapun contoh merancang relasi dasar sebagai berikut :

$\begin{array}{ll}\text { Db_pasien } & \text { : numeric } \\ \text { Domain Id_pasien } & : \text { datetime } \\ \text { Domain Tanggal } & : \text { datetime } \\ \text { Domain jam } & : \text { numeric } \\ \text { Domain Id_dokterPengirim } & : \text { numeric } \\ \text { Domain Id_karyawan } & : \text { numeric }\end{array}$

Db_pasien

(Id_pasien

id_pasien NOT NULL,

Tanggal

Tanggal NOT NULL,

Jam

Jam

NOT NULL,

Id_dokterPengirim

Id_dokterPengirim NOT NULL,

Id_karyawan

Id_karyawan NOT NULL,

Id_detailPasien

Id_detailPasien NOT NULL,

Primary key (Id_pasien));

Foreign key (Id_dokterPengirim) references Db_dokterPengirim (Id_dokterPengirim) ON UPDATE CASCADE ON DELETE NO ACTION,

Foreign key (Id_karyawan) references Db_karyawan (Id_karyawan) ON UPDATE CASCADE ON DELETE NO ACTION,

Foreign key (Id_detailPasien) references Db_detailPasien (Id_detailPasien) ON UPDATE CASCADE ON DELETE NO ACTION;

Db_pemeriksaan

Domain Id_pemeriksaan : numeric

Domain keluhanSakit : variable length character string,Length 50

Domain diagnosa $\quad$ : variable length character string, Length 100

Domain Id_karyawan : numeric

Db_pemeriksaan

(Id_pemeriksaan

Id_pemeriksaan

NOT NULL,

keluhanSakit

keluhanSakit

NOT NULL,

diagnosa

diagnosa

NOT NULL,

Id_karyawan

Id_karyawan

NOT NULL, 
Primary key (Id_pemeriksaan));

Foreign key (Id_karyawan) references Db_karyawan (Id_karyawan) ON UPDATE CASCADE ON DELETE NO ACTION;

Memilih organisasi file bertujuan untuk menentukan organisasi file yang efisien untuk masing-masing basis relasi. Pemilihan organisasi file diambil berdasarkan organisasi file yang digunakan oleh MySQL.

Tahap selanjutnya dari perancangan fisik adalah memilih indeks. Untuk meningkatkan performa dari sistem sewaktu mencari data, dibuatlah indeks pada tabel-tabel yang telah dibuat. Indeks dibuat berdasarkan field yang sering digunakan dalam proses pencarian. Berikut ini adalah daftar indeks untuk masing-masing tabel yang ada (Tabel 2).

Tabel 2

Contoh Pemilihan Indeks

\begin{tabular}{lllll}
\hline No & \multicolumn{1}{c}{ Relasi } & \multicolumn{1}{c}{ Field } & Nama Indeks & $\begin{array}{c}\text { Clustered / Non } \\
\text { Clustered }\end{array}$ \\
\hline 1 & Db_pasien & Id_pasien & Db_pasien_idx & Non Clustered \\
& & Id_karyawan & & Clustered \\
& & Id_dokterPengirim & & Clustered \\
& & namaPasien & & Clustered \\
& & Id_karyawan & & Clustered \\
\hline 8 & Db_pemeriksaan & Id_pemeriksaan & Db_pemeriksaan_idx & Non Clustered \\
& & Id_karyawan & & Clustered \\
\hline
\end{tabular}

Selanjutnya, dilakukan estimasi disk space. Tujuan dari langkah ini adalah untuk menghitung kapasitas penyimpanan yang dibutuhkan oleh basis data. Perkiraan kapasitas setiap tabel adalah sebagai berikut (Tabel 3):

Tabel 3

Contoh Estimasi Disk Space

\begin{tabular}{llr}
\hline \multicolumn{1}{c}{ Field } & \multicolumn{1}{c}{ Data type } & \multicolumn{1}{c}{ Ukuran } \\
\hline Id_pasien & Int & 6 \\
tanggal & datetime & 8 \\
jam & Int & 6 \\
Id_karyawan & Int & 6 \\
Id_dokterPengirim & Int & 6 \\
Id_detailPasien & Int & 6 \\
\hline total & $\mathbf{3 8}$ \\
\hline \multicolumn{2}{c}{ dengan asumsi 40 pasien per hari dan perkiraan } \\
\multicolumn{3}{c}{ selama 1 tahun } \\
\hline $38 * 40 * 27 * 12=492480$ bytes \\
\hline
\end{tabular}

Tahap terakhir dari perancangan fisik yaitu merancang mekanisme keamanan. Suatu basis data merepresentasikan informasi penting bagi perusahaan dan keamanan dari informasi merupakan faktor penting. Dalam keamanan ada dua tipe keamanan, yaitu keamanan sistem dan keamanan data. Keamanan sistem mengatur pengaksesan dan penggunaan basis data. Caranya adalah dengan membuat 
halaman login sebelum masuk ke halaman utama dari sistem. Dalam halaman login, user diminta untuk memasukkan username dan password. Sehingga user yang tidak memiliki username tau tidak memiliki password maka tidak akan bisa masuk ke sistem. Sedangkan untuk keamanan data, berhubungan dengan relasi basis data (tabel atau relasi) dan aksi yang user lakukan terhadap relasi tersebut, misalnya aksi pemilihan, pengisian, pengubahan, dan penghapusan data. Berikut ini akan ditampilkan matriks referensi silang antara user dan relasi. Tujuannya adalah untuk membatasi hak akses user terhadap relasi yang ada.

\section{Perancangan Aplikasi}

Perancangan aplikasi berikut merupakan rancangan yang akan digunakan oleh perusahaan. Di dalam perancangan aplikasi terdapat rancangan struktur menu. Kemudian dilanjutkan dengan pembuatan state transition diagram (STD), rancangan layar (Gambar 6), dan spesifikasi prosesnya.

Basis data yang dibuat telah melewati tahap evaluasi yang meliputi 5 kriteria yang diujicobakan, yaitu domain integrity, entity integrity, references integrity, enterprise constraint dan security (Rika \& Ricky, 2009). Hasil dari evaluasi domain integrity menunjukkan bahwa semua tabel yang ada dalam basis data telah dilakukan uji coba, setiap atributnya harus diisi dengan batasan yang telah ditentukan sebelumnya. Hasil dari evaluasi entity integrity menunjukan bahwa semua primary key pada setiap tabel tidak diperbolehkan untuk diisi dengan "NULL" value. Hasil dari evaluasi references integrity menunjukan bahwa semua foreign key pada setiap tabel yang memiliki foreign key terhubung dengan tabel lain dengan menggunakan referential integrity menggunakan rules on delete cascade, on update cascade, di mana jika data pada suatu tabel dilakukan perubahan maka tabel lain juga akan ikut berubah, sedangkan jika data pada suatu tabel dihapus, maka data pada tabel lain yang terhubung melalui foreign key akan ikut terhapus.

Hasil dari evaluasi enterprise constraint menunjukan bahwa setiap data baru akan disimpan ke dalam basis data yang telah ada, maka akan dilakukan pengecekan terlebih dahulu, di mana data baru yang akan disimpan harus menyesuaikan constraint yang telah dibuat, agar data tersebut tetap konsisten dengan data yang lainnya. Dan hasil dari evaluasi security menunjukan bahwa semua tabel yang telah dilakukan uji coba, kesemuanya telah dapat berjalan sesuai dengan mekanisme yang ditentukan.

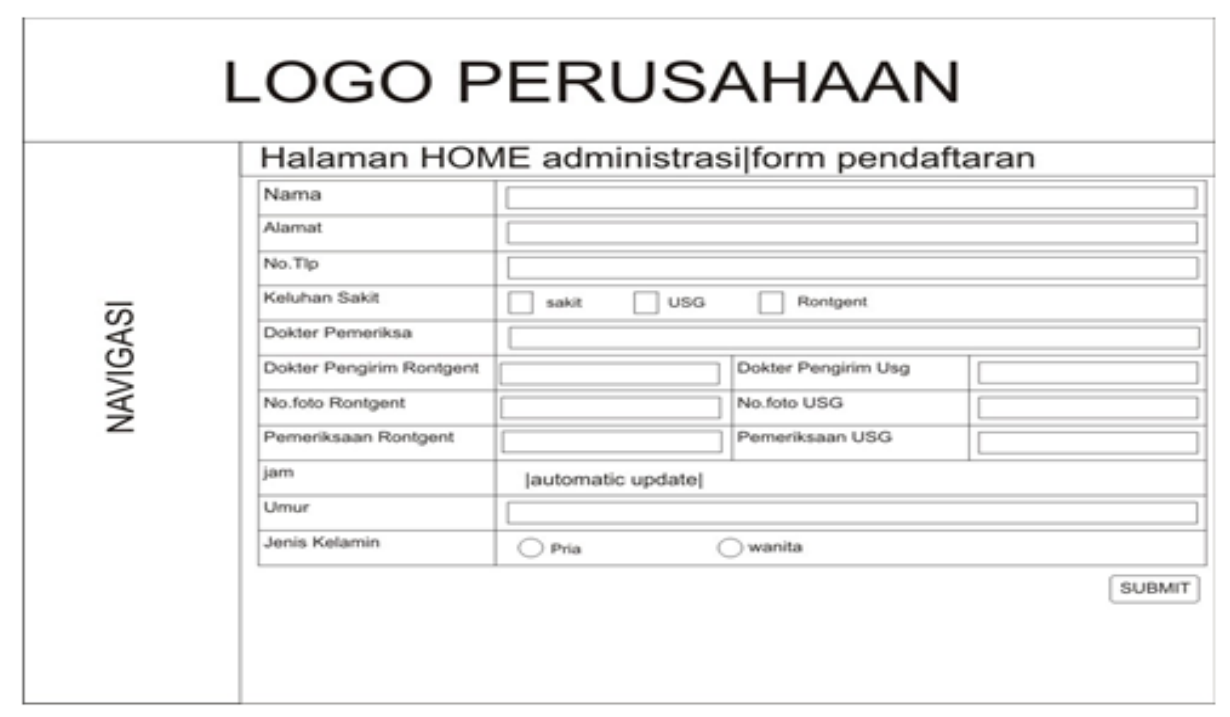

Gambar 6. Rancangan layar pendaftaran. 


\section{PENUTUP}

Simpulan yang dapat diambil dari penelitian ini adalah basis data yang dibuat menghasilkan integritas data yang baik tanpa adanya redundance 'kemubaziran' serta mekanisme keamanan yang baik sehingga menghasilkan informasi yang cepat dan akurat dalam mendukung kegiatan operasional dan dalam pengambilan keputusan pada klinik. Dengan menggunakan basis data, seluruh data lebih terintegrasi, di mana bila ada data yang berubah pada suatu tabel, data pada tabel lain yang berhubungan dengan tabel tersebut akan ter-update secara otomatis. Klinik dapat melakukan manipulasi data seperti insert dan update sehingga dapat meminimalkan kesalahan user pada saat penginputan data dan kesalahan data. Aplikasi yang dibuat membantu dan mempermudah pencarian dan pengaksesan data karena data sudah dibuat terstruktur dan terorganisir, dalam hal ini medical record pasien lebih terorganisir. Tingkat keamanan data lebih terjamin karena hanya yang memiliki IdLogin dan password saja yang dapat melakukan akses data sesuai dengan hak akses yang dimiliki oleh masing-masing user.

\section{DAFTAR PUSTAKA}

Connolly, T. and Begg, Carolyn E. (2005). Database System: A Practical Approach to Design, Implementation, and Management (4th ed.). Boston: Addison Wesley Publishing.

Indrajani. (2008). Sistem Basis Data dalam Paket 5 in 1. Jakarta: Elex Media Computindo.

Kembaran, S., Praptimah, Y. E., Nur’ainingsih, D., Warmansya, J. (2008). Optimalisasi Rancangan Sistem Informasi Rawat Inap Menggunakan DFD - ERD Dikombinasi Dengan User Interface. Jurnal Informatika Komputer. http://jurnal.pdii.lipi.go.id/

Rika \& Ricky, Michael Yoseph. (2009). Analisis dan Perancangan Sistem Informasi Laboratorium Rumah Sakit Kanker Dharmais Dengan Menggunakan Total Architecture.

Tierney, W. M, Rotich, J. K, Smith, F. E., Bii, J., Einterz, R. M, Hannan, T. J. (2002) Crossing the "Digital Divide": Implementing an Electronic Medical Record System in a Rural Kenyan Health Center to Support Clinical Care and Research. Proceeding of the AMIA Symposium, 792-795. Diakses dari http://www.mendeley.com/research/crossing-the-digital-divideimplementing-an-electronic-medical-record-system-in-a-rural-kenyan-health-center-tosupport-clinical-care-and-research/.

Tierney, W.M., Achieng, M., Baker, E., Bell, A., Biondich, P., Braitstein, P., Kayiwa, D., Kimaiyo, S., Mamlin, B., McKown, B., Musinguzi, N., Nyandiko, W., Rotich, J., Sidle, J., Siika, A., Were, M., Wolfe, B., Wools-Kaloustian, K., Yeung, A., Yiannoutsos, C. (2010). Experience Implementing Electronic Health Records in Three East African Countries. Openmrs Consortium. Diakses dari http://www.ncbi.nlm.nih.gov/pubmed/20841711. 